\title{
ROUSSEAU E AS CONDIÇÕES DA LIBERDADE REPUBLICANA
}

\author{
Luiz Felipe Netto de Andrade e Silva Sahd ${ }^{1}$
}

\section{Resumo:}

A intenção desse artigo é examinar as condições da liberdade republicana no pensamento político de Jean-Jacques Rousseau a partir da distinção entre as noções de independência e liberdade. A independência consiste em não depender de nenhum poder - pessoal ou coletivo - e a estar isento de toda lei. Para Rousseau, somente a lei pode instaurar a verdadeira liberdade, porque não visa nem exprime interesses particulares, possibilitando a superação e eliminação de toda e qualquer arbitrariedade. Rousseau, ao distanciar-se do liberalismo nascente, mantendo-se na tradição republicana, não considera a coerção legal uma forma de limitação da liberdade, mas a sua melhor garantia. A liberdade dos cidadãos não está ameaçada pela interferência da lei, mas pelas relações de dominação que estabelecem formas de dependência.

Palavras-chave: Independência; Liberdade; Lei; Soberania; Vontade Geral.

\section{ROUSSEAU AND THE CONDICTIONS OF THE REPUBLICAN LIBERTY}

\begin{abstract}
:
The intention of this article is to examine the conditions of republican freedom in Jean-Jacques Rousseau's political thinking from the distinction between the notions of independence and freedom. Independence consists in not depending on any power personal or collective - and to be exempt of all law. For Rousseau, only the law can establish true freedom, because it neither seeks nor expresses particular interests, making it possible to overcome and eliminate any arbitrariness. Rousseau, distancing himself from nascent liberalism, keeping to the republican tradition, does not consider legal coercion a form of limitation of freedom, but his best guarantee. Citizens' freedom is not threatened by the interference of the law, but by the relations of domination that establish forms of dependence.
\end{abstract}

Keywords: Independence. Freedom. Law. Sovereignty. General Will.

\section{Introdução}

Uma distinção inicial se coloca a todos que pretendem ler a noção de liberdade no pensamento político de Rousseau a partir da tradição republicana, a distinção defendida por Benjamin Constant entre a liberdade dos Antigos e a liberdade dos

\footnotetext{
1 Doutor em Filosofia pela Universidade Estadual de Campinas (2000). Atualmente é professor associado 4 da Universidade Federal do Ceará. E-mail: felipesahd@yahoo.com.br.
} 
Modernos. Embora, a abordagem das condições da liberdade republicana não necessita do olhar de Constant, a sua ênfase no esquema que opõe as duas tradições apontando para a combinação entre elas, permitirá a compreensão do debate profícuo entre liberais e republicanos, cujos contornos auxiliarão na localização da posição de Rousseau. Além disso, a segunda grande ruptura operada pelos pensadores do liberalismo do século XVIII que participaram do nascimento da modernidade, será ressaltada a partir da concepção inovadora da liberdade do indivíduo como independência a respeito de toda forma de autoridade e da sociedade como ordem espontânea. O indivíduo fora do mundo das seitas protestantes como o sujeito cartesiano mestre e possuidor da natureza são os ancestrais distantes da concepção liberal da liberdade como independência e soberania. Como esta liberdade será canalizada e como seres soberanos e independentes instituirão a sociedade, cooperando ao invés de se matarem? Como o liberalismo responderá à objeção de Hobbes e evitará a guerra de todos contra todos? A resposta será encontrada no surgimento da "liberdade dos Modernos" e da sociedade civil, uma sociedade de indivíduos unidos por um mesmo objetivo, a satisfação das necessidades humanas, capazes da associação e cooperação nestas condições bem mais estáveis e eficazes do que sob o efeito do constrangimento e da dominação.

Foi Benjamin Constant, em seu ensaio De la liberté des Anciens comparée à celle des Modernes (1819), que melhor descreveu o novo mundo da liberdade dos Modernos. Seu diagnóstico da Revolução Francesa está fundada sobre o sentido das transformações irreversíveis que a sociedade sofreu. Ele inicia o texto com uma descrição da liberdade dos Antigos: "Esta liberdade é composta da participação ativa no poder coletivo e jamais no desfrute pacífico da independência individual" (CONSTANT, 1997, p.206). Depois, ele desenvolve uma crítica severa à Revolução Francesa e sua concepção "antiga" e inadaptada da liberdade como participação popular nos negócios públicos que, durante o período do Terror, legitimou a violência contra todos que recusam a sua participação no processo revolucionário. A participação ativa dos cidadãos nas decisões políticas impõe a renúncia à independência privada, a constituição de instituições que mantenham a igualdade, impeça o crescimento das fortunas, proscrevam as distinções, opondo-se à influência “dos ricos, dos talentos e das virtudes”. Instituições similares, entre as quais Constant cita o ostracismo, a censura e as leis agrárias, violações diretas à liberdade individual,

\begin{tabular}{|l|l|l|l|l|}
\hline Q Povista Qialectus & Ano 4 & n. 10 & Janeiro - Julho 2017 & p. 221-231 \\
\hline
\end{tabular}


cujo núcleo é o gozo da propriedade. Em páginas severas, o autor condena Rousseau e a ilusão de mais uma vez impor a liberdade dos Antigos aos indivíduos modernos, uma vez que tratam-se de duas configurações sociais e históricas incompatíveis.

A liberdade dos Antigos consiste em exercer o poder político de maneira coletiva e direta, os cidadãos exercem influência real no poder. A submissão dos indivíduos é sem reservas à autoridade do todo social. Para Constant, há uma contradição insuperável em comparação à liberdade dos Modernos, a participação direta na política com ínfima liberdade individual ${ }^{2}$. Para reforçar a tese da inadequação marcada pelo tempo, o autor acrescenta entre as duas concepções de liberdade uma noção de progresso segundo a qual há um requinte geral que leva a valorizar diferentemente o coletivo e o individual. Não se trata de defender uma noção do progresso na liberdade cujo efeito seria tornar a sociedade mais livre, mas tão somente do enriquecimento da vida privada dos cidadãos ao ponto em que a independência individual tornou-se uma "necessidade" intransponível, sendo assim inútil exigir o seu sacrifício ${ }^{3}$. Embora crítico contundente, Constant não toma partido a favor do mundo moderno contra os Antigos, pois estava consciente e inquieto dos perigos representados pelo desinteresse da vida política, a delegação da soberania e da representação. A inquietação assume os contornos da antecipação da advertência de Alexis Tocqueville (TOCQUEVILLE, 1992, p.838). Suas reflexões evocam as observações de Rousseau sobre os perigos da não participação política, em especial aquela contida no Livro III, capítulo XV do Contrato social (ROUSSEAU, 1964, pp.428-31). A soberania política do cidadão moderno foi erodida pela ausência de interesse e investimento individuais: "O perigo da liberdade moderna está em que, absorvidos pelo gozo da independência privada e na busca de interesses particulares, renunciemos demasiado facilmente a nosso direito de participar do poder político"

\footnotetext{
${ }^{2}$ A liberdade moderna consiste no direito do indivíduo não se submeter a nada senão às leis. É o direito à propriedade privada, à liberdade de expressão, de ir e vir sem a repressão da vontade arbitrária de um ou vários indivíduos. É a liberdade sem coerção de Hobbes. Constant insiste, portanto, nos perigos da perda dessa liberdade: "O perigo da liberdade antiga estava em que, atentos unicamente à necessidade de garantir a participação no poder social, os homens não se preocupassem com os direitos e garantias individuais" (CONSTANT, 1997, p.616).

3 "A independência individual é a primeira das necessidades ("besoins") modernas. Consequentemente, não se deve nunca pedir seu sacrifício para estabelecer a liberdade política” (CONSTANT, 1997, p.608).
}

\begin{tabular}{|l|l|l|l|l|}
\hline Q Ponista Dialectus & Ano 4 & n. 10 & Janeiro - Julho 2017 & p. 221-231 \\
\hline
\end{tabular}


(CONSTANT, 1997, p.616). A conclusão do discurso apela à plateia para o desenvolvimento de duas noções da liberdade política que combine uma com a outra ${ }^{4}$.

\section{As condições da liberdade ${ }^{5}$}

Rousseau critica seus antecessores, entre eles Hobbes, por não terem refletido sobre o direito, mas somente sobre o fato, não fornecendo resposta satisfatória à questão da legitimidade da ordem política. Neste sentido, ele sustenta que há uma clara diferença - e mesmo uma oposição - entre independência, que reenvia a uma situação de fato, e liberdade, que se refere a uma situação de direito: "Tem-se confundido a independência e a liberdade. Essas duas coisas são tão diferentes que elas chegam a se excluir mutuamente" (ROUSSEAU, 1964, p.841).

A independência consiste em não depender de nenhum poder - pessoal ou coletivo - e a estar isento de toda lei. O homem independente vive somente sob a lei de sua própria natureza, que é somente um princípio causal que o faz agir e que varia em função das solicitações e dos obstáculos que o cerca. Essa lei de sua natureza, tributária de suas paixões e de suas motivações, visa preferencialmente o prazer e o gozo. A independência é assim um estado onde o homem se encontra quando não há outra relação nem outra regra de suas ações a não ser aquela de seus próprios apetites. Por isso, falar de independência é falar das causas que determinam ou que motivam os homens a agir, mostrando que essas causas se encontram nele.

Essa independência originária e natural é transformada em interdependência, quando se estabelecem os primeiros vínculos sociais. A solução ao impasse dessa transformação não é o retorno ao isolamento perfeito da condição natural, pois isso tornou-se inacessível a criaturas que necessitam do concurso de seus semelhantes para sobreviver. Se a independência original não está mais disponível, a solução buscada por Rousseau é a de encontrar uma forma de associação "pela qual cada um, unindose a todos, só obedece, contudo, a si mesmo, permanecendo tão livre quanto antes" (ROUSSEAU, 1964, p.360).

\footnotetext{
4 "Longe, pois, Senhores, de renunciar a alguma das duas espécies de liberdade de que vos falei, é preciso aprender a combiná-las" (CONSTANT, 1997, p.616).

${ }_{5}^{5}$ Embora a relação de Rousseau com o republicanismo mereça um tratamento diferenciado em relação aos contemporâneos (BIGNOTTO, 2010, p.86), pode-se consultar o conteúdo e a importância da tradição republicana, que alimentou o pensamento democrático moderno paralelamente à tradição liberal inaugurada por Locke, as obras de M. Viroli (1988), J.-F. Spitz (1995), M. Abensour (1997) e Q. Skinner (1998).
}

\begin{tabular}{|l|l|l|l|l|}
\hline Q Povista Dialectus & Ano 4 & n. 10 & Janeiro - Julho 2017 & p. 221-231 \\
\hline
\end{tabular}


A cláusula fundamental do contrato social proposto é a alienação total, sem reservas, para que a dependência seja radical, não mais parcial e ocasional, mas geral e inflexível, que não comporte arbitrariedade. Ela consiste na manifestação consciente de cada associado em dar-se completamente à comunidade. Da reciprocidade de doação sem restrições, é possível obter uma união tão perfeita que cada um ganha o que cedeu, pois “dando-se a todos não se dá a ninguém e, não existindo um associado sobre o qual não se adquira o mesmo direito que se lhe cede sobre si mesmo, ganha-se o equivalente de tudo que se perde" (ROUSSEAU, 1964, p.361).

A essência do contrato é o desaparecimento das vontades particulares numa unidade que as absorve: os homens, enquanto particulares, se anulam para dar lugar a uma entidade coletiva que não é um simples agregado de forças, mas um novo ser, artificial, composto por aqueles que participaram do pacto associativo, um corpo moral ontologicamente distinto daqueles que contribuíram para a sua formação. $O$ movimento dessa pessoa pública, chamada de república, provém da vontade geral, definida não como a vontade de todos, mas como a vontade do Todo, que manifesta o que há de comum entre todas as vontades particulares, sem que delas dependa. Enquanto as vontades particulares buscam a realização de interesses privados, o objetivo da vontade geral é dirigir as ações do corpo político de acordo com a finalidade de sua instituição, que é o bem comum.

A vontade geral manifesta-se na lei civil, que anima o corpo político, dandolhe movimento e direção. A lei civil é considerada a melhor garantia contra o arbítrio de vontades particulares, em razão de sua generalidade. Esta generalidade é formal, por emanar de uma vontade que é sempre universal, e material, no sentido de não ter outra finalidade senão o interesse público: “Quando digo que o objeto das leis é sempre geral, por isso entendo que a lei considera os súditos como corpo e as ações como abstratas, e jamais um homem como um indivíduo ou uma ação particular... Chamo pois de república todo o Estado regido por leis, sob qualquer forma de administração que possa conhecer, pois só nesse caso governa o interesse público e a coisa pública" (ROUSSEAU, 1964, p.379). Para Rousseau, somente a lei pode instaurar a verdadeira liberdade, porque não visa nem exprime interesses particulares, possibilitando a superação e eliminação de toda e qualquer arbitrariedade. Além disso, o cidadão que obedece à lei não depende de outra vontade senão da sua própria vontade, já que a submissão à vontade geral é a submissão à própria vontade. Ao dar

\begin{tabular}{|l|l|l|l|l|}
\hline Govista Qialectus & Ano 4 & n. 10 & Janeiro - Julho 2017 & p. 221-231 \\
\hline
\end{tabular}


seu livre consentimento a algo que está acima de sua vontade particular, compreendendo e assimilando o significado da vontade geral, o cidadão faz dela a sua regra de conduta.

Ao submeter-se a lei, expressão da vontade geral, o cidadão pode então ser considerado livre, pois os direitos que a lei lhe confere são reconhecidos como legítimos por todos. Todo cidadão necessita da convicção de que suas ações são compatíveis com a união realizada. Precisa ter consciência da aprovação dada de suas ações pela vontade geral. Enquanto o cidadão não dispõe de uma regra de direito que lhe permite desqualificar os obstáculos a sua ação como ilegítimos e fazer apelo à força coligada do conjunto de seus concidadãos para suprimi-los, ele vive privado de liberdade. Ser livre consiste em desfrutar da proteção e da segurança proporcionadas pela lei, que autoriza e reconhece como legítimas as ações autorizadas pela vontade geral: "vós vereis em todo lugar a liberdade reclamada, mas sempre sob a autoridade das leis, sem as quais a liberdade não pode existir, e sob as quais se é sempre livre, de qualquer modo que se seja governado" (ROUSSEAU, 1964, p.811).

A lei é a melhor indicação do que é conforme ao interesse público, do que é legítimo e justo numa determinada sociedade civil. Por ser a expressão da vontade geral, ela fornece um critério para determinar as ações que são permitidas e proibidas para todos os membros do corpo político independentemente de seus interesses particulares: "as leis não são mais do que as condições da associação civil. O povo, submetido às leis, deve ser o seu autor. Só àqueles que se associam cabe regulamentar as condições da sociedade" (ROUSSEAU, 1964, p.380). A consulta à vontade geral pela via da deliberação é assim o melhor meio de resolver a questão da equidade numa sociedade. Ao manifestar os princípios de legitimidade dessa sociedade, a lei estabelece um sistema de reciprocidade entre direitos e deveres, sendo a melhor indicação do que é conforme ao interesse comum. Para Rousseau, somente uma sociedade civil que delibera sobre as regras e a repartição dos bens é composta de cidadãos que não têm nada a temer em relação a sua vida e aos seus bens. Eles podem se sentir seguros, pois não possuem nem fazem nada que a comunidade não tenha anteriormente autorizado e reconhecido como legítimos. Mas onde os princípios legais não são o produto de uma deliberação comum, que é o melhor meio de resolver o problema da equidade numa sociedade civil, não pode haver nenhuma segurança desse gênero.

\begin{tabular}{|l|l|l|l|l|}
\hline Q Ronista Dialectus & Ano 4 & n. 10 & Janeiro - Julho 2017 & p. 221-231 \\
\hline
\end{tabular}


Ao submeter-se à lei estabelecida pela deliberação comum, os cidadãos dependem apenas da vontade do corpo político do qual fazem parte, garantido sua liberdade, pois as suas condutas não são afetadas nem estão expostas a uma vontade particular. Elas são determinadas pela vontade geral, que é a vontade de cada membro da associação enquanto dirigida ao interesse comum. Ao compreender e assimilar o significado da vontade geral, os cidadãos absorvem a lei em sua consciência e fazem dela a sua regra de conduta, assegurando a liberdade como um direito e como um dever: "é-se livre quando submetido às leis, porém não quando se submete a um homem, porque nesse último caso obedeço à vontade de outrem, enquanto obedecendo à lei não obedeço senão à vontade pública que tanto é minha como de quem quer que seja" (ROUSSEAU, 1964, p.492). Ao contrário, onde as relações sociais não são regidas pela expressão da vontade geral, cada um está exposto e vulnerável à vontade de todos os outros, podendo ser constrangido a moldar sua conduta a partir da vontade de outros. É essa dependência pessoal em relação à vontade de outrem que é a principal inimiga da liberdade. O que determina a heteronímia da vontade não são os obstáculos ou impedimentos que a ação encontra, mas sua natureza. A liberdade não é suprimida pela restrição de movimento imposta por obstáculos exteriores, mas pelo fato desses obstáculos emanarem da vontade arbitrária de outrem ${ }^{6}$.

Rousseau procura estabelecer de maneira muito clara a diferença entre obediência e servidão. Ele identifica liberdade com obediência às leis, que impõem o mesmo constrangimento a todos; ao contrário, equipara a ausência de liberdade com privilégio, quando alguns indivíduos têm o poder de isentar a si mesmos do constrangimento imposto a outros: "Não há liberdade sem leis, nem aonde alguém está acima das leis... um povo livre obedece, mas não serve; tem líderes, mas não senhores; obedece às leis, mas somente às leis, e é por causa da força das leis que não é forçado a obedecer a homens... a liberdade provém sempre das leis, ela reina ou se extingue com elas" (ROUSSEAU, 1964, p.842). A liberdade não está assim em relação com as causas da ação, mas com sua legitimidade. Refere-se a uma situação de direito, tributária da legitimidade da ordem política. Ela não é o efeito da ação do poder político, graças a efetividade de seus meios de coerção, que garante uma área

\footnotetext{
6 "A liberdade consiste menos em fazer sua vontade do que em não estar sujeito à vontade de outrem; ela consiste ainda em não submeter a vontade de outrem à nossa vontade" (ROUSSEAU, 1964, p.841).

\begin{tabular}{|c|c|c|c|c|}
\hline Rovista 2 idolectus & Ano 4 & n. 10 & Janeiro - Julho 2017 & p. $221-231$ \\
\hline
\end{tabular}
}


na qual cada um pode desenvolver suas potencialidades sem constrangimentos, mas é principalmente o efeito de uma ordem política legítima, graças a qual cada um tem assegurado o poder de fazer tudo o que as leis permitem, porque sabe que o outro tem o dever de não por obstáculos à realização das ações autorizadas pelas leis. Nesse sentido, a liberdade consiste menos em manter os outros fora de nossa esfera de ação ou de evitar a sua interferência arbitrária do que em criar neles um dever de não impedir as ações que a lei nos dá o direito de executar.

A questão fundamental para Rousseau não é, dessa maneira, saber o que motiva os homens à obediência, mas determinar o que cria neles esse autêntico dever de obediência. Se uma regra é imposta por uma vontade arbitrária, ela não tem o poder de obrigar em consciência aqueles que ela subjuga, mas apenas o poder de constrangê-los pelo medo da sanção. Tal regra, mesmo que tenha sido consentida, instaura o reino da força, ao consagrar relações de dominação e de dependência. Para Rousseau, a ordem política não pode ser reduzida a um sistema de restrições legais. Não se trata de estabelecer um poder coercitivo capaz de dissuadir os indivíduos de interferir nas ações dos outros, mas de estabelecer uma ordenação política capaz de criar o dever de respeitar a lei.

A força da lei só pode ser proveniente, segundo Rousseau, do reconhecimento por parte dos cidadãos de sua legitimidade. Essa legitimidade não depende apenas do consentimento, uma vez que é possível estabelecer uma regra consentida que, ao invés de banir a dominação, a consagra e a institucionaliza. Para obrigar aqueles a quem se dirige, além de consentida, a lei deve ser equitativa, isto é, deve visar o bem comum, sem impor sacrifícios a uns em benefício de outros. Ela precisa ainda não apenas ser benéfica para todos, mas permitir uma repartição igual desses mesmos benefícios ${ }^{7}$. Para Rousseau, é preciso então garantir certa igualdade de condições entre os cidadãos, ao menos relativa, que permita encontrar uma regra que seja igualmente útil a todos, pois, se as condições sociais forem muito desiguais, não é possível haver interesse comum. Não é suficiente, por exemplo, atribuir a autoridade a magistrados eleitos pelo povo e controlados pelo povo, se a sociedade é composta por cidadãos muito ricos que os corrompe e os compra. Também é inútil conferir direitos

\footnotetext{
7 "Se quisermos saber no que consiste, precisamente, o maior de todos os bens, qual deve ser a finalidade de todos os sistemas de legislação, verificar-se-á que se resume nestes dois objetivos principais: a liberdade e a igualdade. A liberdade, porque qualquer dependência particular corresponde a outro tanto de força tomada ao corpo do Estado, e a igualdade, porque a liberdade não pode subsistir sem ela" (ROUSSEAU, 1964, p.391).
}

\begin{tabular}{|l|l|l|l|l|}
\hline Q Povista Dialectus & Ano 4 & n. 10 & Janeiro - Julho 2017 & p. 221-231 \\
\hline
\end{tabular}


idênticos ao conjunto dos cidadãos se alguns são tão pobres que são obrigados a viver na dependência de outros em troca de sua subsistência: "quando à igualdade, não se deve entender por essa palavra que sejam absolutamente os mesmos os graus de poder e de riqueza, mas, quanto ao poder, que esteja distanciado de qualquer violência e nunca se exerça senão em virtude do posto e das leis e, quanto à riqueza, que nenhum cidadão seja suficientemente opulento para poder comprar um outro e não haja nenhum tão pobre que se veja constrangido a vender-se "(ROUSSEAU, 1964, p.3912). Logo, não há liberdade, para Rousseau, numa sociedade na qual os cidadãos são constrangidos pela força e na qual a desigualdade social determina que alguns tenham sua existência determinada pela vontade de outros. A desigualdade social e a injustiça aparecem como poderosos obstáculos à liberdade, porque constrangem os cidadãos a situações de dependência e dominação em relação aos outros. A liberdade é assim tributária de uma ordem política justa e legítima, capaz de estabelecer, por meio de suas leis, deveres e direitos iguais a todos os cidadãos, e capaz de criar nos cidadãos a obrigação moral de respeitar essas leis.

\section{Conclusão}

$\mathrm{Na}$ tradição do pensamento liberal, a liberdade tem sido concebida como ausência de impedimentos ou de constrangimentos para a ação; e, por ser uma forma de constrangimento que limita a ação, a lei civil tem sido considerada uma restrição à liberdade dos indivíduos (BERLIN, 1969). Se a coerção legal é justificada por diminuir o nível de coerção legal, já que impede os outros indivíduos de interferir na área delimitada por ela, e se é aceita, porque assegura o espaço garantido por ela, essa coerção legal nunca deve ser maior do que a necessária para a compatibilização da liberdade de todos. Além disso, de acordo com a perspectiva liberal, se é preciso restringir a liberdade no interesse da própria liberdade, protegendo-a de seus excessos, ela só pode ser limitada com este objetivo e não em nome de outros valores como igualdade, bem-estar ou justiça social. Enfim, no pensamento liberal, a lei não produz liberdade para aquele que é constrangido por ela. A liberdade só é produzida para aqueles que são protegidos pela coerção legal. A lei proporciona liberdade, mas sempre no polo oposto ao qual é exercido.

Já a tradição republicana enfatiza que a coerção legal é uma limitação intrínseca à própria liberdade, que só se estabelece a partir de restrições igualmente

\begin{tabular}{|l|l|l|l|l|}
\hline Q Ronista Dialectus & Ano 4 & n. 10 & Janeiro - Julho 2017 & p. 221-231 \\
\hline
\end{tabular}


impostas a todos os membros do corpo político, sejam eles cidadãos ou governantes. A lei civil é considerada uma forma de interferência que não compromete a liberdade, porque não estabelece uma relação de dominação. Ao contrário, ao proteger os cidadãos contra o domínio de poderes arbitrários, emancipando-os das condições de dependência, ela garante a liberdade.

A diferença de avaliação entre o pensamento liberal e o republicano sobre o papel das leis civis está fundamentada principalmente em diferentes concepções de liberdade, construídas no interior dessas duas tradições de pensar a política.

$\mathrm{Na}$ tradição republicana, a liberdade é caracterizada pela ausência de dominação e não pela ausência de interferência, como no pensamento liberal, visto que a simples ausência de interferência não garante a liberdade. $\mathrm{O}$ exemplo mais utilizado dessa ausência de interferência que mantém a dominação é o do senhor benevolente que não interfere nas ações de seu servo, permitindo a ele um amplo campo de ação, ou do servo engenho que sabe lidar com seu senhor e tem a sua disposição um amplo espaço de ação. Em ambos os casos o servo continua dependente da vontade do senhor, que pode interferir ou não, sem considerar o interesse ou a opinião do servo, que será afetado pela interferência. Essa dependência marca a falta de liberdade, porque revela a dominação do senhor sobre o servo. Assim, no pensamento republicano, ser livre significa não estar sob o domínio de outra pessoa, mesmo que ela não o exerça, pois aquilo que constitui a dominação é a capacidade de interferir de maneira arbitrária, deixando o outro numa situação de dependência.

Para o pensamento republicano, ao contrário, é possível haver interferência sem dominação, nos casos em que a interferência não é arbitrária e não depende da simples vontade de outra pessoa, mas é estabelecida pelo consentimento e é realizada tendo em vista o benefício daquele que é afetado pela intervenção. Este é o caso da lei civil que, ao buscar o interesse geral e ser controlada por aqueles que são afetados pela sua restrição, é uma forma de interferência que não compromete a liberdade, porque não estabelece uma relação de dominação. Ao contrário, garante a liberdade dos cidadãos, ao protegê-los contra o domínio de poderes arbitrários, emancipando-os das condições de dependência.

Rousseau, ao distanciar-se do liberalismo nascente, mantendo-se na tradição republicana, não considera a coerção legal uma forma de limitação da liberdade, mas

\begin{tabular}{|l|l|l|l|l|}
\hline Q Povista Qialectus & Ano 4 & n. 10 & Janeiro - Julho 2017 & p. 221-231 \\
\hline
\end{tabular}


Luiz Felipe Netto de Andrade e Silva Sahd

a sua melhor garantia. A liberdade dos cidadãos não está ameaçada pela interferência da lei, mas pelas relações de dominação que estabelecem formas de dependência. Para o pensador genebrino, não basta manter a liberdade natural dos súditos. É preciso garantir a liberdade dos cidadãos e isto só é possível por meio das leis civis.

\section{Referências Bibliográficas:}

ABENSOUR, M. La Démocratie contre l'État - Marx et le moment machiavélien. Paris: PUF, 1997.

BERLIN, I. Four Essays on Liberty. Oxford: Oxford University Press, 1969.

BIGNOTTO, N. As aventuras da virtude. As ideias republicanas na França do século XVIII. São Paulo: Companhia Das Letras, 2010.

CONSTANT, B. Écrits politiques 1814-1829. Paris: Gallimard, 1997.

ROUSSEAU, J.-J. Oeuvres complètes, Tomo III. Paris: Gallimard, Pléiade, 1964.

SKINNER, Q. Liberty before Liberalism. Cambridge: Cambridge University Press, 19998.

SPITZ, J.-F. La liberté politique. Paris: PUF, 1995.

TOCQUEVILLE, A. Oeuvres complètes, Tomo II. Paris: Gallimard, Pléiade, 1992.

VIROLI, M. La théorie de la société bien ordonnée chez Jean-Jacques Rousseau.

Berlin: Walter de Gruyter, 1988.

\begin{tabular}{|l|l|l|l|l|}
\hline Qevista Dialectus & Ano 4 & n. 10 & Janeiro - Julho 2017 & p. 221-231 \\
\hline
\end{tabular}

